\title{
Actinomicetoma plantar en un paciente sin factores de riesgo
}

\author{
Alejandro Kral', Gabriel Castillo', Carolina Galindo', Marcelo Wolff', \\ Juan Pablo Uribe², Carla Morong ${ }^{2}$ y Ignacio Beddings ${ }^{3}$
}

\section{Plantar actinomycetoma in a patient without risk factors}

A case of plantar actinomycetoma without risk factors is presented, which was diagnosed by hystopatological analysis of a foot biopsy because of the suspicion of neoplasia. Since the patient did not fully respond to the firstline therapy antibiotics, a 24-weeks doxycycline regime was started, achieving a satisfactory response. Finally, a brief discussion on plantar mycetomas is presented.

Keywords: Madura foot; mycetoma; actinomycetoma; actinomycosis.

Palabras claves: Pie de Madura; micetoma; actinomicetoma; actinomicosis.

\section{Introducción}

$\mathrm{E}$ 1 micetoma es una infección crónica de la piel y tejidos blandos que suele afectar a las extremidades inferiores, habitualmente en la región plantar, recibiendo el nombre de "pie de Madura". Según su etiología puede clasificarse como eumicetoma (cuando es producido por hongos) o actinomicetoma (causado por bacterias). Las diferencias epidemiológicas y microbiológicas varían según el tipo de micetoma, aunque comparten la presentación clínica, como un aumento de volumen nodular con fistulización y secreción, y a la microscopía, extrusión de gránulos de diversos colores según su etiología ${ }^{1}$.

La infección por Actinomyces de extremidades inferiores es poco frecuente. Su hábitat habitual es la orofaringe, tracto gastrointestinal y genital femenino.

A continuación, se presenta un caso de actinomicetoma plantar, en que a partir de una biopsia realizada por sospecha de una neoplasia, se logró el diagnóstico final. Recibió antimicrobianos de segunda línea logrando resolución completa de la lesión plantar.

\section{Caso clínico}

Varón de 47 años, con antecedente de una dislipidemia. Era residente de un área urbana de la Región Metropolitana, sin trabajos en áreas rurales ni viajes al extranjero. Consultó por primera vez en la atención primaria por un cuadro de dos años de evolución de un aumento de volumen doloroso en la región plantar derecha que le imposibilitaba la marcha, sin antecedente de trauma. En dicha oportunidad, no se describieron signos de inflamación local, ni sistémicos. Sin solución de continuidad de la piel ni salida de contenido purulento. A la anamnesis dirigida, no presentaba síntomas consuntivos. Fue derivado a Traumatología, donde se solicitó una ecografía y una resonancia magnética (RM) (Figura 1).

A partir de resultado de la RM, fue derivado a cirugía vascular bajo la sospecha de una malformación arterio-venosa capilar, donde se indicaron tres sesiones de escleroterapia con disminución discreta del volumen, sin lograr aminorar el dolor. Dada la mala evolución se sospechó una neoplasia y se realizó una biopsia incisional de la lesión plantar, seis meses después de la primera consulta (Figura 2).

El informe histopatológico demostró un tejido celular subcutáneo y fibroconectivo con presencia de numerosos gránulos de azufre con filamentos grampositivos rodeados de un proceso inflamatorio agudo purulento, compatible con un micetoma por Actinomyces sp. (Figuras 3 y 4).

Tras este resultado el paciente fue derivado a Infectología. Al examen físico, destacaba un aumento de volumen nodular plantar derecho, sin signos de infección local ni sistémica, y sin signos de fistulización ni supuración. Se inició tratamiento antimicrobiano con amoxicilina $1 \mathrm{~g}$ cada ocho horas, vía oral, con disminución importante del aumento de volumen, recuperación significativa de la marcha, aunque con persistencia de dolor (Figura 5). Se realizó una RM de control, ocho semanas post-inicio de tratamiento, que demostró solo una leve disminución de la masa (Figura 6).

Tras 11 semanas de tratamiento, y debido a una pobre respuesta clínica, se decidió cambiar a doxiciclina 100 mg cada 12 horas, vía oral, logrando remisión del dolor y recuperación de la marcha. Se realizó una nueva RM de control que mostró una marcada disminución de tamaño de la lesión (Figura 7).

A la fecha de esta publicación el paciente ha completado 24 semanas de terapia con doxiciclina, con buena respuesta clínica.
'Facultad de Medicina, Universidad de Chile, Hospital Clínico San Borja Arriarán. Santiago, Chile.

${ }^{2}$ Hospital Clínico San Borja Arriarán. Santiago, Chile. ${ }^{3}$ Pontificia Universidad Católica de Chile. Santiago, Chile.

Los autores declaran no tener conflictos de interés en relación al trabajo. No hubo fuentes externas de financiamiento.

Recibido: 19 de marzo de 2019 Aceptado: 9 de julio de 2019

Correspondencia a: Alejandro Kral alejandro.kral@gmail.com 


\section{Caso Clínico}

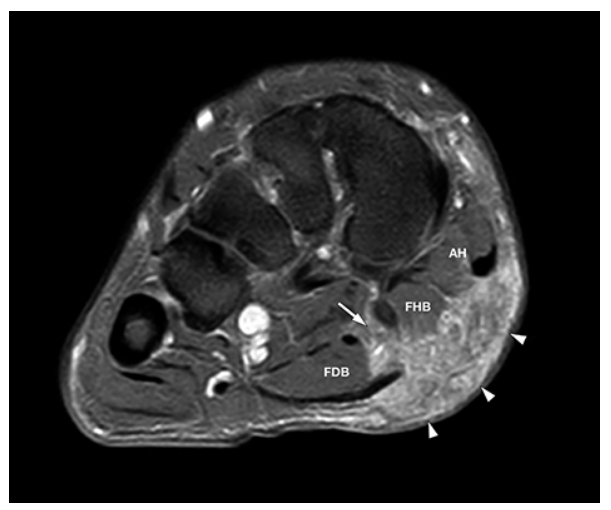

Figura 1. Masa en el tejido celular subcutáneo del aspecto medial del mediopié (cabezas de flecha blancas), de bordes irregulares, con extensión intermuscular hacia planos profundos (flecha blanca). La lesión contacta el margen superficial de los músculos abductor hallucis (AH), flexor hallucis brevis (FHB) y flexor digitorum brevis (FDB).

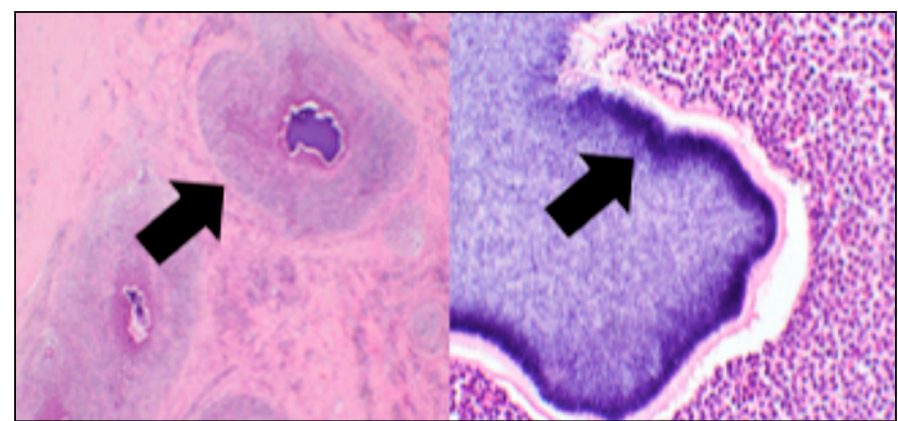

Figura 3. Gránulos de azufre color morado oscuro, rodeados por infiltrado polimorfonuclear con tinción de hematoxilina-eosina (flechas).

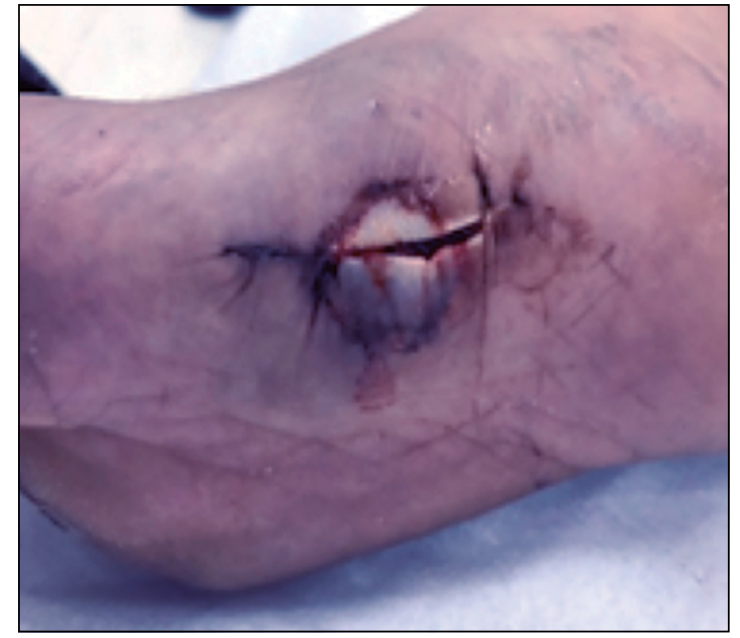

Figura 2. Lesión plantar sometida a una biopsia incisional.

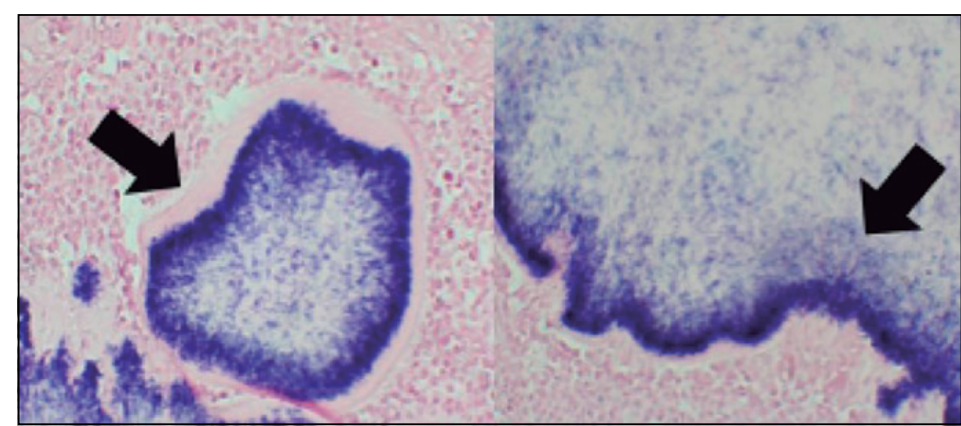

Figura 4. Filamentos con tinción de Gram positivos (flechas).

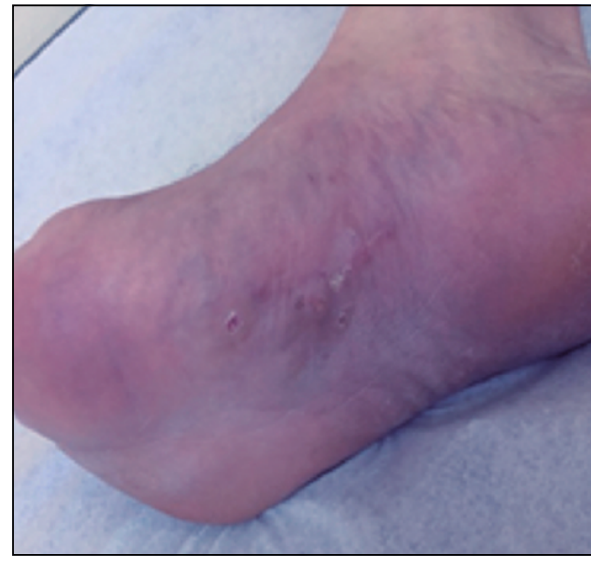

Figura 5. Lesión plantar tras 10 semanas de tratamiento antimicrobiano.

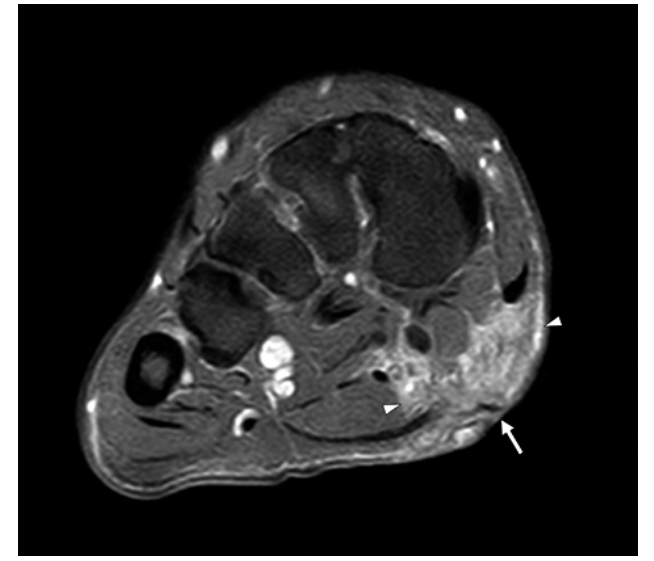

Figura 6. Se observa leve disminución de volumen de la masa del tejido celular subcutáneo del aspecto medial del mediopié (cabeza de flecha blanca). Son visibles cambios cicatriciales en relación a sitio de biopsia de la lesión (flecha blanca).

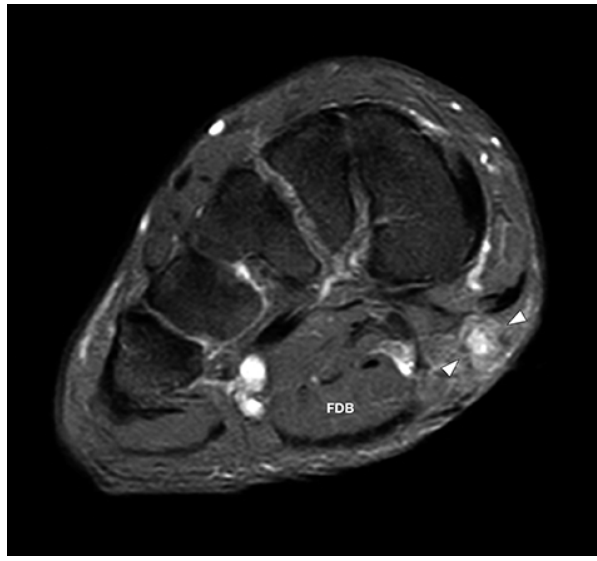

Figura 7. Marcada disminución de tamaño de la lesión expansiva del mediopié (cabezas de flecha blancas), con menor compromiso de planos profundos intermusculares. 


\begin{tabular}{|lll|}
\hline \multicolumn{2}{|l|}{ Tabla 1. Adaptado de: Mycetoma: a unique neglected tropical disease. Lancet Infect Dis 2016; 16: 100-12. } \\
\hline Característica & Eumicetoma & Actinomicetoma \\
\hline Microorganismos frecuentes & Madurella mycetomatis & Nocardia brasiliensis, Actinomyces madurae, Actinomadura pelletieri, Streptomyces somaliensis \\
\hline Zona endémica & África, India & Latinoamérica \\
\hline Grupo etáreo & $20-40$ años & $40-50$ años \\
\hline Zonas anatómicas más afectadas & Pies (80\%), manos (6\%) & Extra-acral con más frecuencia (tórax, abdomen, cabeza) \\
\hline Evolución & Menos agresiva & Más agresiva \\
\hline Fístulas & Pocas & Muchas \\
\hline Senos & Proliferativos, protuberantes & Planos \\
\hline Compromiso óseo & Tardío & Precoz \\
\hline Diseminación linfática & Ocasional & Frecuente \\
Análisis patológico macroscópico & Bien definido, con cápsula & Mal definido, sin cápsula \\
\hline Análisis patológico microscópico & Tinción PAS (+) & Tinción Gram positiva \\
\hline Tratamiento & Cirugía y antibioticoterapia & Antibioticoterapia \\
\hline
\end{tabular}

\section{Discusión}

El micetoma es una infección granulomatosa crónica y mutilante de la piel y tejidos blandos, que puede comprometer articulaciones y hueso. Afecta hasta en el $80 \%$ de los casos, las extremidades inferiores (piernas y pie) ${ }^{1}$. Geográficamente, en zonas más áridas es más prevalente el actinomicetoma, producido por bacterias filamentosas de lento crecimiento, mientras que en zonas tropicales es más frecuente el eumicetoma. Se describe un "cinturón del micetoma" que afecta a países de ingresos bajos y medios, entre $30^{\circ}$ de latitud norte y $15^{\circ}$ de latitud sur $^{2}$, correspondiendo Sudán al país con mayor prevalencia (14,5 por 1.000 habitantes $)^{3}$. En ese país, $70 \%$ son causados por Madurella mycetomatis. Por otro lado, México reportó una media de 73 casos por año, actinomicetomas casi en su totalidad, más frecuentemente causados por Nocardia brasiliensis ${ }^{4}$.

Actinomyces spp. son bacilos grampositivos anaerobios facultativos que normalmente colonizan la región orofaríngea, tracto digestivo y genital femenino. Son factores predisponentes para desarrollar el actinomicetoma, el trauma local con disrupción de los tejidos y la diabetes mellitus. El rol de la inmunosupresión no está claro y es importante notar que la mayoría de los casos se presentan en personas inmunocompetentes. Es más frecuente en varones, entre 20-40 años ${ }^{5}$.

En relación a su patogénesis, las especies de Actinomyces son parte de la microbiota humana descrita previamente. La bacteria ingresa a partir de una disrupción de la barrera mucosa con diseminación directa a los tejidos, sin diseminación linfática ni hematógena. Por ende, las adenopatías no son frecuentes. Actinomyces puede suprimir algunas de las funciones inmunitarias del hospedero. Son quimiotácticos, activan la blastogénesis y estimulan la liberación de enzimas lisosómicas de los polimorfonucleares y macrófagos. Al ser fagocitadas no pueden eliminarse y, por lo tanto, se definen como parásitos intracelulares facultativos similares a Mycobacterium tuberculosis. Esto explica la fuerte tendencia a causar una inflamación granulomatosa crónica de los tejidos blandos ${ }^{5}$.

Es interesante en su patogénesis que en más de $90 \%$ de los casos se cultivan otras bacterias de las lesiones de actinomicosis, tanto abiertas como cerradas. Estas otras bacterias frecuentemente son Streptococcus anaerobios y bacilos gramnegativos. Existiría una sinergia dando un ambiente anaeróbico propicio para el crecimiento de Actinomyces.

La tríada "nódulo subcutáneo indoloro, formación de senos y descarga purulenta con gránulos" es característica $^{5}$. La presentación clínica suele ser indistinguible entre un eumicetoma y actinomicetoma, aunque existen algunas características que permiten diferenciarlos (Tabla 1) ${ }^{1}$. Dado que suele afectar a población de bajo nivel socioeconómico, la consulta suele ser tardía, a lo que se agrega el hecho de que el cuadro clínico en sí es larvado e inicialmente oligosintomático, descartándose muchas veces el antecedente de trauma en el paciente, en relación al variable y extenso período de evolución de la enfermedad 6 .

Los pies y las manos se afectan en más de $80 \%$ de los casos, mientras que los brazos o piernas se afectan en $10 \%$ de los casos. En agricultores que cargan sacos, se ha descrito compromiso lumbar y vertebral ${ }^{6}$. El compromiso de estructuras profundas (nervios, tendones y hueso) puede ocurrir en infecciones de más larga evolución, siendo más frecuente en actinomicetomas que en eumicetomas, así como el compromiso metastásico linfonodal ${ }^{1}$. Dado 
lo anterior, el diagnóstico diferencial suele establecerse con tuberculosis cutánea, granulomatosis por cuerpo extraño, neoplasia (sarcomas de tejidos blandos) y otras infecciones tropicales (esporotricosis, botriomicosis, paracoccidiomicosis, entre otras $)^{7}$.

En ese mismo sentido, al enfrentarse a un paciente con lesiones nodulares en las extremidades inferiores, se deben indagar ciertos datos en la historia clínica que permitan aproximarse al origen del cuadro clínico. Antecedentes tales como: viajes al extranjero, ruralidad, trauma reciente, tiempo de evolución de la enfermedad y la presencia de síndrome consuntivo, orientan hacia diversas etiologías.

De esta forma será posible clasificar de forma genérica, en patologías de origen infeccioso (micetomas, tuberculosis), origen inflamatorias-autoinmune (eritema nodoso, enfermedad de Behcet, poliarteritis nodosa, paniculitis pancreática) y oncológicas (tumores de tejidos blandos y linfomas) ${ }^{8}$.

Un correcto diagnóstico requiere una combinación de aspectos clínicos, análisis microbiológico, histopatológico e imágenes.

Microscópicamente, las lesiones consisten en una zona externa densa de tejido de granulación compuesto de colágeno y fibroblastos. El tejido de granulación forma múltiples localizaciones con un centro purulento que contiene gránulos de azufre rodeados de neutrófilos, microcolonias de Actinomyces, desechos celulares y otros microorganismos asociados. Los gránulos de azufre evaluados con tinción hematoxilina-eosina son diagnósticos. Con la tinción de Gram se logra identificar los gránulos compuestos por filamentos de bacterias (Figura 3 y 4).

Desde el punto de vista microbiológico la tinción de Gram suele ser más útil que el cultivo, por su mayor sensibilidad y porque en la gran mayoría de las veces, este último puede ser negativo por el uso previo de antimicrobianos ${ }^{9}$. Aunque caras y poco disponibles en áreas endémicas, las técnicas de amplificación de $\mathrm{ADN}$ por reacción de polimerasa en cadena (RPC) exhiben una mejor sensibilidad en la identificación del microorganismo causante ${ }^{10,11}$. A la fecha no existen pruebas serológicas de buen rendimiento para el diagnóstico ${ }^{1}$.

La ecografía es útil para distinguir el micetoma de otras masas, dada la presencia de gránulos hiperecogénicos ${ }^{12}$ $\mathrm{y}$ es un buen método en centros que no cuenten con tomografía computada (TC) o RM. La RM es el examen con mayor sensibilidad y es útil además para planificar el abordaje quirúrgico.

Según lo descrito en la literatura médica, en un estudio multicéntrico realizado en Francia entre los años 2000$2014^{6}$, de 28 casos de actinomicosis descritos, la forma abdomino-pélvica fue la más frecuentemente encontrada (nueve pacientes). En sólo dos casos se describía compro- miso de tejidos blandos a partir de un trauma previo, sin antecedentes de inmunosupresión, lo que se asemeja a las características de nuestro caso clínico ${ }^{5}$. Lamentablemente, en nuestro paciente no se pudo realizar la identificación de la especie, habiendo requerido para esto el cultivo de la muestra ${ }^{13}$, o la utilización de técnicas de amplificación y secuenciación molecular. Ya que el motivo por el cual se realizó la biopsia fue por sospecha de una patología neoplásica, sólo se pudo identificar el género, lo que habitualmente ocurre en estos casos cuando no existe la sospecha de un cuadro infeccioso.

En Chile, si bien infrecuente, hay un caso publicado de un adulto inmunocompetente con un micetoma plantar que, tras presentar una lesión de seis años de evolución, se logró el diagnóstico definitivo a través de una biopsia de piel, siendo manejado por 12 meses con cotrimoxazol, de forma satisfactoria ${ }^{14}$.

El tratamiento médico con antimicrobianos es el tratamiento de elección, siendo penicilina en dosis altas y amoxicilina los tratamientos de primera línea para el actinomicetoma. En pacientes alérgicos o que no responden, el uso de cotrimoxazol, doxiciclina, clindamicina y eritromicina ha dado buenos resultados ${ }^{14,15}$, debiéndose prolongar por 6 a 12 meses.

La terapia combinada se ha utilizado en algunos casos, pero datos indican que la terapia médica sola puede ser todo lo que se necesita, incluso con una enfermedad extensa.

En el caso clínico presentado, si bien no se pudo aislar la especie, el cuadro clínico y el estudio histopatológico permitieron hacer el diagnóstico de micetoma por Actinomyces sp. y tras el curso actual de tratamiento antimicrobiano, el paciente ha respondido favorablemente.

En conclusión, creemos relevante la presentación de este caso clínico, tanto por lo infrecuente, como por su forma de presentación, ya que finalmente es la alta sospecha clínica, la que asociada al estudio microbiológico e histológico, permiten confirmar el diagnóstico, y plantear al paciente un tratamiento antimicrobiano adecuado, prolongado y dirigido al agente etiológico.

\section{Resumen}

Se presenta un caso clínico de un actinomicetoma plantar en un paciente sin factores de riesgo, cuyo diagnóstico fue realizado mediante una biopsia de tejido plantar por sospecha de una neoplasia. Dado que el paciente no respondió satisfactoriamente a la terapia de primera línea, debió completar 24 semanas de tratamiento con doxiciclina, a lo cual evolucionó favorablemente. Finalmente, se desarrolla una breve discusión sobre los micetomas plantares. 


\section{Referencias bibliográficas}

1.- Ziljstra E E, van de Sande W W J, Welsh O, Mahgoub E S, Goodfellow M, Fahal A $\mathrm{H}$. Mycetoma: a unique neglected tropical disease. Lancet Infect Dis 2016; 16: 100-12. doi: 10.1016/S1473-3099(15)00359-X.

2.- Rattanavong S, Vongthongchit S, Bounphamala K, Vongphakdy P, Gubler J, Mayxay M. Actinomycetoma in SE Asia: the first case from Laos and a review of the literature. BMC Infect Dis 2012; 12: 349. doi: 10.1186/1471-2334-12349.

3.- Fahal A, Mahgoub el S, El Hassan A M, AbdelRahman M E, Alshambaty Y, Hashim A, et al. A new model for management of mycetoma in the Sudan. PLoS Negl Trop Dis 2014; 8: e3271. doi: 10.1371/journal.pntd.0003271.

4.- López-Martínez R, Méndez-Tovar LJ, Bonifaz A, Arenas R, Mayorga J, Welsh O, et al. Update on the epidemiology of mycetoma in Mexico. A review of 3933 cases. Gac Med Mex 2013; 149: 586-92.

5.- Bettesworth J, Gill K, Shah J. Primary actinomycosis of the foot. A case report and literature review. J Am Col Certif Wound Spec 2009; 1: 95-100. doi: 10.1016/j. jcws.2009.06.004.

6.- Bonnefond $\mathrm{S}$, Catroux M, Menenotte $\mathrm{C}$, Karkowski L, Rolland L, Trouillier S, et al. Clinical features of actinomycosis. A retrospective, multicenter study of 28 cases of miscellaneous presentations. Medicine (Baltimore) 2016; 95: 24: e3923. doi: 10.1097/ MD.0000000000003923.

7.- Welsh O, Vera-Cabrera L, Salinas-Carmona M C. Mycetoma. Clin Dermatol 2007; 25: $195-$ 202. doi:10.1016/j.clindermatol.2006.05.011.

8.- Cho K H. Inflammatory nodules of the leg. Ann Dermatol 2012; 24: 383-92. doi: 10.5021/ ad.2012.24.4.383.

9.- Valour F, Sénéchal A, Dupieux C, Karsenty J, Lustig S, Breton P, et al. Actinomycosis: etiology, clinical features, diagnosis, treatment and management. Infect Drug Resist 2014; 7 : 183-97. doi: 10.2147/IDR.S39601.

10.- Zhi X Y, Li W J, Stackebrandt E. An update of the structure and 16S rRNA gene sequencebased definition of higher ranks of the class Actinobacteria, with the proposal of two new suborders and four new families and emended descriptions of the existing higher taxa. Int J Syst Evol Microbiol 2009; 59: 589-608. doi:10.1099/ijs.0.65780-0.

11.- Steingrube V A, Brown B A, Gibson J L, Wilson R W, Brown J, Blacklock Z, et al. DNA amplification and restriction endonuclease analysis for differentiation of 12 species and taxa of Nocardia, including recognition of four new taxa within the Nocardia asteroides complex. J Clin Microbiol 1995; 33: 3096-101.

12.- Fahal A H, Sheik H E, Homeida M M, Arabi Y E, Mahgoub E S. Ultrasonographic imaging of mycetoma. Br J Surg 1997; 84: 1120-2.

13.- Serrano J A, Sandoval A H. El micetoma. Rev Soc Ven Microbiol 2003; 23: 70-9.

14.- Jerez R, Schafer F, Fich F, García P, León P, González S. Micetoma actinomicótico por Actinomadura madurae. Rev Chilena Infectol 2012; 29: 459-63. http://dx.doi.org/10.4067/ S0716-10182012000400018.

15.- Al Gannass A. Chronic Madura foot: mycetoma and/or Actinomyces spp. or actinomycosis. BMJ Case Rep 2018; 2018. doi:10.1136/bcr-2018224859. 